\title{
Distribuição de oportunidades educacionais: políticas para a escolha da escola em redes municipais de ensino ${ }^{1}$
}

\author{
Educational opportunities distribution: policies for school \\ choice in municipal educational systems
Distribución de oportunidades educativas: políticas para la elección de escuela en sistemas escolares municipales

Ana Lorena Bruel ${ }^{2}$

\section{Resumo}

Os objetivos deste trabalho se concentraram em estudar a política de distribuição de oportunidades educacionais nas redes municipais do Rio de Janeiro e de Curitiba, analisando as mudanças estabelecidas pelas políticas de normatização da matrícula para o Ensino Fundamental nos dois municípios. Ao longo da pesquisa procurou-se conhecer as regras de atribuição de vagas aos estudantes, a partir da construção de uma análise sobre a normatização municipal que regulamenta a matrícula dos estudantes no ensino fundamental e as alterações provocadas pela política implementada. A metodologia de pesquisa envolveu a realização de análise documental e entrevistas com servidores das duas redes de ensino. Os resultados da pesquisa sugerem que a reflexão sobre a democratização do acesso à Educação Básica não se esgota na existência de vagas e atendimento à demanda manifesta, tendo em vista a diversificação de oportunidades e a segmentação das escolas e das famílias que a elas acessam, mesmo nas redes públicas de ensino.

Palavras-chave: Política educacional; Distribuição de oportunidades educacionais; Política de acesso à Educação Básica.

1 Parte deste trabalho foi desenvolvida com financiamento da CAPES. Uma versão inicial deste artigo foi apresentada na Reunião Científica Regional da ANPED - Sul (2014).

2 Doutora em Educação. Professora na Universidade Federal do Paraná. E-mail: analorena@ufpr.br 


\begin{abstract}
The objectives of this study were to study the distribution of educational opportunities policy in the municipal educational systems of Rio de Janeiro and Curitiba, analyzing the changes established by the policies of normalization of enrollment for elementary education in both municipalities. Throughout the research, we sought to know the rules for assigning students, based on the construction of an analysis about the municipal regulation that defines the students enrollment in elementary education and the changes provoked by that implemented policy. The research methodology involved documentary analysis and interviews with workers of the two educational systems. The research results suggest that the reflection about the acess democratization to Basic Education is not exhausted in terms of vacancies existence and attendance to the manifest demand, considering the opportunities diversification and the schools and families segmentation that access them, even in public education systems.
\end{abstract}

Keywords: Educational policy; Educational opportunities distribution; Access Policy to Basic Education.

\title{
Resumen
}

Los objetivos de este trabajo se centró en el estudio de la política de distribución de oportunidades educativas en las redes municipales de Río de Janeiro y Curitiba, analisando los cambios establecidos por la políticas de normalización de la matricula para la enseñanza primaria en ambas ciudades. Durante la investigación buscamos comprender las reglas de asignación para los estudiantes, a partir de la construcción de un análisis de la ordenanza municipal que regula el registro de los estudiantes de la escuela primaria y los cambios provocados por la política aplicada. La metodología de investigación implicó el análisis de documentos y entrevistas con los trabajadores de las dos redes de enseñanza. Os resultados de la investigación sugieren que la reflexión sobre la democratización del acceso a la educación básica no se limita a la existencia de plazas y satisfacción de la demanda expresa, considerando las oportunidades de diversificación y la focalización de las escuelas y de las familias que acceden, incluso en las escuelas públicas.

Palabras clave: Política educativa; Distribución de oportunidades educativas; Política de acceso a la educación básica. 


\section{Políticas de distribuição de oportunidades educacionais: entre o Estado e o mercado}

Há grande diversidade entre as formas de atribuição das escolas aos estudantes, ou de distribuição dos estudantes entre as instituições escolares em diferentes países e em regiões ou municípios dentro de um mesmo país. De acordo com Van Zanten (2009, p. 6-7), na maior parte dos países a escolha da escola é objeto de controle do Estado. A autora identifica quatro formas típico-ideais: 1) inexistência total de escolha; 2) atribuição oficial com possibilidade oficial de troca; 3) modelo de quotas, quando há escolha, mas a burocracia estatal garante proporcionalidade entre etnias (ou outros critérios que buscam reduzir segregação); 4) livre escolha.

O Brasil não possui uma política nacional de distribuição de oportunidades educacionais. Os dispositivos presentes na legislação nacional (Lei n. ${ }^{\circ}$ 8069/90 e Lei n. ${ }^{\circ}$ 9394/96) preveem regras bastante gerais, como o direito à vaga em escola pública e gratuita próxima da residência do estudante como um direito de todos. Aspectos da legislação e normatização serão analisados no segundo tópico deste artigo. Por hora, é importante destacar que as regras nacionais são bastante gerais e que o detalhamento dos procedimentos para a distribuição dos estudantes entre as escolas públicas fica a critério dos sistemas e redes de ensino.

Desta maneira, as formas de distribuição de vagas escolares não se verificam no Brasil como regras nacionais, mas como normatização local. Estudos realizados por Souza e Oliveira (2003); Costa e Koslinski (2009); Resende et al (2011), para citar alguns exemplos, verificaram a existência de estratégias de escolha da escola pelas famílias mesmo em municípios onde não havia uma política explícita de escolha, ou ainda, observaram a existência de procedimentos de escolha (oculta) mesmo em municípios onde a regra previa atribuição da escola ao estudante por instâncias do poder público, com restrição formal de escolha pelas famílias.

A análise construída neste artigo procura apresentar reflexões a partir de um quadro teórico com referência em autores internacionais contemporâneos que estudam o tema e que foram pouco discutidos na literatura nacional, com o objetivo de apresentar novos contornos que possam contribuir para o debate. Este trabalho assume a hipótese de que as estratégias de distribuição das oportunidades escolares variam entre dois polos opostos: em um extremo estão os procedimentos que apostam na definição organizada pelos sistemas educacionais com pequena possibilidade ou restrição de escolha pelas famílias; e em outro extremo encontramse aqueles que investem na escolha das famílias com impedimento ou restrição de seleção por parte dos sistemas educacionais.

Entre esses extremos, encontram-se múltiplas alternativas para a organização dos procedimentos formais de distribuição dos estudantes entre as escolas em um sistema de ensino, que misturam, em diferentes graus, possibilidades de seleção das escolas pelas famílias e de seleção das famílias pelas escolas ou outros níveis da burocracia estatal. Percebe-se que essa gradação está relacionada à adoção de políticas com presença mais forte de características de mercado ou com presença mais marcante do Estado.

De um lado, as políticas de distribuição de oportunidades que conferem à administração pública o poder de atribuir o estabelecimento de ensino ao estudante com restrição de escolha das famílias estão fundamentadas em perspectivas de fortalecimento do papel do Estado. De outro lado, as políticas que conferem às famílias o poder de escolher as instituições de ensino baseiam-se em concepções que defendem o fortalecimento do indivíduo e redução do poder de intervenção do Estado.

Os estudos sobre distribuição de oportunidades educacionais que tomam como referência a análise dos processos de seleção das escolas pelos pais e de seleção dos estudantes pelos estabelecimentos de ensino, em espaços onde há políticas explícitas de school choice e quase-mercado ou não, reconhecem grande variedade de procedimentos, que não se concentram nos polos extremos identificados acima. Para uma representação gráfica dessa variação, propõe-se o seguinte quadro: 


\section{Quadro 1 - Variação das políticas de distribuição de vagas de acordo com a possibilidade de escolha da escola pelas famílias e regulação do poder público}

\begin{tabular}{|c|l|l|l|}
\hline Relação entre escolha das famílias e seleção & Incentivo à escolha & Possibilidade de escolha & Restrição à escolha \\
\hline Restrição à seleção & & & \\
\hline Possibilidade de seleção & & & \\
\hline Incentivo à seleção & & & \\
\hline
\end{tabular}

Fonte: Bruel, 2014, p. 16.

O Quadro 1 procura associar visualmente graus diferenciados de procedimentos que incentivam, possibilitam ou restringem a escolha do estabelecimento escolar pelas famílias, a graus diferenciados de ações do poder público que restringem, possibilitam ou incentivam a intervenção do poder público, das próprias escolas ou de diferentes níveis da burocracia estatal, independentemente dos critérios adotados, para seleção e atribuição de vagas aos estudantes.

As políticas que se situam nas áreas da tabela marcadas em cinza mais claro são aquelas que se orientam pela atribuição da escola ao estudante. Os alunos podem ser selecionados por diferentes critérios, como: localização geográfica de sua moradia e do estabelecimento de ensino, resultados em testes de rendimento escolar, histórico acadêmico do estudante, avaliação vocacional, etc. Muitas dessas políticas se fundamentam na defesa de uma perspectiva republicana de compreensão do Estado como provedor de bens sociais, entre os quais a educação, e responsável pelo controle sobre sua distribuição, oferta e garantia. A França, a Alemanha, a Inglaterra ${ }^{3}$ são exemplos de países que adotam ou adotaram estratégias como essas.

Já nas áreas da tabela marcadas em preto e cinza mais escuro estariam as políticas que estabelecem modelos de organização de quase-mercados escolares e introduzem a possibilidade de escolha da escola pelos pais dos alunos, tratada na literatura como school choice. Diferentes países optaram por estratégias distintas para realização dessas escolhas e para a distribuição das oportunidades escolares entre as famílias, mas é possível distinguir características recorrentes: a mudança do centro de decisão em relação à distribuição, transferindo-o das burocracias educacionais para a família, muitas vezes aliando a escolha das famílias ao impedimento de processos de seleção dos alunos pelas escolas. Dentre as políticas de school choice, que habitualmente são acompanhadas de políticas de disseminação de informações, descentralização de decisões e avaliação externa, algumas estabelecem processos de aleatorização da distribuição, procurando proporcionar chances iguais de acesso de alunos de diferentes estratos sociais às escolas.

Há experiências de instituição de políticas de quase-mercado em países como a Inglaterra, o Chile, a Austrália e a Nova Zelândia, bem como em alguns estados e cidades dos Estados Unidos da América, como Boston (GORARD, 2003; GLENN, 2009; MAROY, 2006). Algumas dessas experiências serão analisadas neste artigo.

As políticas de distribuição de oportunidades educacionais geram muitas polêmicas e deram origem a vários debates, tanto acadêmicos quanto ideológicos, que procuram evidenciar positividades e problemas relacionados à restrição de escolha e atribuição das escolas aos estudantes pela burocracia estatal, bem como relacionados à organização de quase-mercados e escolha da escola pela família.

Para o desenvolvimento deste trabalho, interessa conhecer principalmente os debates que envolvem as políticas de quase-mercado e escolha, pois os dois municípios analisados incorporaram-nas de alguma forma. Portanto, dar-se-á ênfase às reflexões construídas em torno dessas perspectivas. De um lado, é possível citar a ideia de livre escolha como um arauto da democracia e da regulação do quase-mercado como uma forma racional de distribuição das oportunidades escolares; de outro, encontram-se as críticas relacionadas à redução do papel do Estado, à

3 A Inglaterra pode ser considerada exemplo desse modelo de política no período anterior à Reforma de 1988, que promoveu mudanças na política de distribuição de oportunidades educacionais no sentido de incorporação de estratégias de escolha. 
manutenção das distâncias sociais, à falta de justiça social e equidade na oferta de educação com qualidade para todos. Considera-se que os estudos sobre a constituição de quase-mercados escolares podem contribuir para analisar a experiência de escolha da escola pela família implementada na rede municipal de ensino da cidade do Rio de Janeiro a partir do ano letivo de 2010 e na rede municipal de ensino da cidade de Curitiba a partir de 2015.

Gorard et al. (2003) afirmam que o Reino Unido se consolidou como um laboratório social pela extensão das políticas que promovem competição entre escolas e escolha dos pais. A Reforma Educacional instituída em 1988 substituiu a alocação dos estudantes nas escolas pela burocracia estatal, de acordo com a residência da família, pela escolha da escola pelos pais em um quase-mercado com diversidade de escolas.

Antes da aprovação do "School Standards and Framework Act 1988", foi observada uma grande variedade nos processos de distribuição de oportunidades escolares em estudos sobre a alocação de alunos nas escolas do sistema educacional inglês. A Reforma procurou substituir a distribuição dos alunos nas escolas realizada pelas autoridades educacionais locais pela escolha dos pais num mercado que apresentasse diversidade de opções. Contudo, mesmo com o estabelecimento de critérios explícitos, estudos demonstraram a permanência de considerável variação na aplicação desses critérios (GORARD et al., 2003, p. 8).

A Reforma, baseada no princípio de transparência dos processos de distribuição de oportunidades educacionais, estabeleceu uma mudança de legislação que concedeu às famílias o direito de expressarem suas preferências por qualquer escola (independentemente de região geográfica ou proximidade entre a moradia e a escola) e negou o direito da escola de recusar a matrícula de qualquer pessoa. Essa mudança é significativa na medida em que transfere o poder de seleção antes nas mãos das escolas e autoridades educacionais locais para as mãos das famílias.

Os princípios de defesa do modelo de quase-mercado escolar se sustentam sobre as noções de liberdade de escolha, equidade e competição entre escolas, a fim de tornarem-se populares e bem-sucedidas. Um dos principais contra-argumentos apresentados à lógica do quase-mercado se refere à possibilidade de desconstrução da estrutura do Estado de Bem-Estar, cuja ação é concebida como necessária para alcançar alguma forma de justiça social numa economia capitalista.

Para Gorard et al. (2003), as políticas de school choice e participação das famílias se justificam como um antídoto para a estratificação social e escolar, pois procuram estender o privilégio de escolha a membros da sociedade que não o possuíam antes. Os pesquisadores compreendem segregação ou estratificação escolar como uma crescente separação entre grupos socioeconômicos, com uma concentração das camadas mais desfavorecidas da sociedade em algumas escolas, e dos grupos mais favorecidos em outras. A política de escolha do estabelecimento escolar pela família poderia criar uma heterogeneidade maior entre os estudantes da mesma instituição, reduzindo a estratificação entre escolas.

Os resultados obtidos pelos pesquisadores em estudo de larga escala envolvendo escolas e estudantes da Inglaterra e País de Gales indicam que houve redução progressiva de segregação entre as escolas depois da instauração das políticas de quase-mercado, bem como não se observou redução dos índices de equidade associado à escolha dos pais, o que leva Gorard et al. (2003, p. 72) a questionar a afirmação simplista de que "markets lead to segregation"4.

Nos Estados Unidos da América há grande diversidade entre as políticas de distribuição de oportunidades educacionais, tendo em vista o modelo de organização federativa que confere alto grau de autonomia aos estados. Em estudo realizado a partir da experiência da cidade de Boston (Massachusetts) sobre a constituição de quase-mercados escolares regulamentados pelo poder público, Glenn (2009) indica os programas de escolha controlada como possibilidade de distribuição das vagas das escolas atendendo ao máximo possível os desejos indicados pelas famílias e a necessidade de equilíbrio (racial e social) em cada escola.

4 Tradução livre: mercados conduzem à segregação (GORARD et al., 2003, p. 72). 
O autor avalia que o mercado, por si só, pode se tornar mais uma causa para a segregação e a desigualdade escolar, aumentando os desequilíbrios já existentes nos sistemas escolares. Para ele, a mão invisível do mercado não é suficiente. Uma boa estratégia de mercado deve prever: procedimentos para assegurar igualdade de acesso, manter a confiança no processo e promover a integração; divulgação eficaz e aconselhamento individual para que os pais possam tomar decisões conscientes e informadas sobre as escolas; medidas para assegurar que a escolha seja real.

Nas análises apresentadas, Glenn (op. cit.) indica que é possível verificar que as famílias de classe média se beneficiam com os processos de escolha, em detrimento das famílias mais pobres, que demonstram menor potencial para dominar e manipular o sistema de "consumidores de escolas". O estudo desenvolvido por ele analisa experiências de constituição de mercados escolares em Boston, cuja intenção, de acordo com o pesquisador, não é instalar um capitalismo selvagem, com competição desenfreada, mas uma abordagem de "mercado justo", equitativo, procurando oferecer a possibilidade de comparação entre os benefícios e aumentar a participação dos pais.

Para o autor, o processo de escolha, como apoio adequado - sobretudo em relação às informações sobre as escolas - pode fortalecer os pais, além de levá-los a assumir a responsabilidade pelas decisões de escolarização de seus filhos. Com o objetivo de superar os procedimentos de segregação escolar e acirramento das desigualdades pela ação da escolarização, Glenn defende a experiência de "Escolha Controlada"5, realizada em Boston a partir dos anos 1980, que procurou unificar as ideias de escolha dos pais com a atribuição de escolas aos estudantes com base na distribuição geográfica, como possibilidade de respeitar as escolhas das famílias utilizando estratégias informatizadas para a distribuição das vagas entre os que as demandam.

Os procedimentos para a realização da escolha controlada envolvem os pais de novos estudantes ou daqueles que estão em transição para o próximo nível. As famílias são chamadas para visitar os centros de informação a fim de receber aconselhamento, com materiais explicativos em várias línguas, antes de apresentar suas escolhas. Um programa de computador passou a fazer a distribuição das vagas, atendendo ao máximo possível as escolhas e a necessidade de equilíbrio racial em cada escola.

A escolha controlada possui quatro objetivos: 1. Igualdade de acesso a todos os alunos, independente da região em que cada família pode viver; 2 . Envolvimento dos pais com informação sobre as escolas; 3 . Eliminação da garantia de vaga de acordo com a residência; 4. Melhorar o equilíbrio racial de cada escola (GLENN, 2009). As estratégias adotadas pelas políticas de distribuição de oportunidades em Boston, assim como na Inglaterra, podem ser identificadas como políticas que incentivam a escolha das famílias e ao mesmo tempo incentivam a intervenção da burocracia estatal, na medida em que essa escolha se realiza de forma controlada pelo poder público. Seria possível localizar este modelo na região em branco do Quadro 1, no canto inferior esquerdo.

Em pesquisas sobre a distribuição de oportunidades escolares em Israel, Yair (1996) desenvolveu uma análise procurando compreender o funcionamento de quase-mercados educacionais no âmbito local, considerando a existência de "schools in specific market niches" ${ }^{6}$ (YAIR, 1996, p. 454), a possibilidade de mobilidade dos estudantes entre tipos diferentes de escola e a estrutura hierárquica criada pela situação de competição entre os estabelecimentos escolares. O autor construiu o conceito de ecologia de mercado para indicar como esses aspectos interagem. Para ele, não se pode considerar as ações dos indivíduos ou das escolas isoladamente, uma vez que a opção de um sujeito por uma determinada escola limita a escolha dos demais, da mesma forma que a existência de escolas muito procuradas só é possível se houver escolas com menor procura para atender a demanda excedente.

5 Essa política diz respeito essencialmente à distribuição de vagas em escolas que oferecemEnsino Médio, chamadas de magnet schools.

6 Tradução livre: existência de escolas em nichos específicos de mercado. (YAIR, 1996, p. 454) 
Para o autor, a escolha se baseia na forma como as vagas estão distribuídas entre as escolas e na ecologia do mercado educacional. O que caracteriza a ecologia de um mercado escolar é a existência de uma estrutura de oportunidades diferenciadas, estabelecidas entre um conjunto de escolas circunscrito territorialmente. Os quase-mercados educacionais são organizados como um mercado com "closed-positions" (YAIR, 1996, p. 456), o que significa que há um número fixo e pré-determinado de vagas em cada instituição escolar, que limita as oportunidades de acesso a cada uma das escolas.

Em sistemas de posições fechadas, como analisado por Yair (op. cit.), novas pessoas só podem ocupar espaços dentro do sistema se uma posição se torna "vaga" e esta vaga só existe se alguém sai do sistema e deixa de ocupá-la. Neste sentido, a escolha não depende apenas de motivações individuais na medida em que a infraestrutura do quase-mercado educacional, ou estrutura de oportunidades, produz o palco para a realização das escolhas.

Assim, os conceitos relacionados à constituição de quase-mercados escolares são utilizados para estudar contextos em que não há políticas explícitas de escolha ou disputa entre instituições, mas se percebe a existência de uma ecologia de mercado, ou seja, relações entre oferta e demanda que mantém um quase-mercado em funcionamento, ainda que sem uma regulamentação explícita do poder público. No Brasil, que não possui uma política nacional de organização de mercados ou escolha da escola pelos pais, como já indicado anteriormente, esta perspectiva de análise foi assumida como uma possibilidade por vários pesquisadores, como Souza e Oliveira (2003) ao estudar as políticas de avaliação nacional, por Costa e Koslinski (2009) em pesquisa sobre acesso dos estudantes a escolas públicas no município do Rio de Janeiro, e por Resende et al (2011) em estudo sobre a escolha da escola em Belo Horizonte e o perfil das famílias, apenas para citar alguns exemplos. Sendo que Costa e Koslinski (2009) propõem o conceito de quase-mercado escolar oculto para estudar casos em que quasemercados se estabelecem sem que haja uma publicização das regras estabelecidas para o seu funcionamento.

As evidências empíricas dos diferentes estudos apresentados neste artigo indicam que há sempre espaço para a intervenção das famílias e algum grau de liberdade para a escolha da escola. Mesmo em lugares onde se verifica a restrição formal e legal à escolha, as pesquisas indicam a existência de procedimentos e estratégias assumidas pelas famílias a fim de procurar e obter a vaga para seus filhos nas escolas que preferem (VAN ZANTEN, 2009; POUPEAU e FRANÇOIS, 2008). Por outro lado, a existência de políticas de escolha não significa que todas as famílias serão atendidas em relação às suas demandas, tendo em vista que os quase-mercados escolares se caracterizam por possuírem posições fechadas, o que pode gerar um descompasso entre a oferta e a demanda, sobretudo em estabelecimentos de ensino considerados de prestígio.

Ao mesmo tempo, também foi possível verificar a presença do poder público regulamentando os procedimentos de distribuição de oportunidades, mesmo onde há políticas de quase-mercado escolar instituídas. Não se trata, portanto, de aniquilar o poder de escolha das famílias e tampouco de impedir a intervenção do poder público. O que se verificou, em cada caso em particular, foram políticas que combinam diferentes graus de escolha das escolas pelas famílias e procedimentos de intervenção da burocracia estatal sobre a distribuição das oportunidades educacionais. As ações das famílias e as ações realizadas por pessoas que ocupam diferentes cargos nos níveis da burocracia estatal podem ser oficiais e estar previstas nas normas que conduzem os processos de atribuição das escolas aos estudantes ou podem ser oficiosas e se realizar entre brechas construídas por dentro do próprio sistema.

\section{Aspectos legais e normativos que moldam as estruturas de oportunidades de acesso ao Ensino Fundamental em duas redes públicas municipais: Rio de Janeiro e Curitiba}

Do ponto de vista do estabelecimento de normas para a organização do ensino, é possível afirmar que o princípio de descentralização acompanhou todo o processo de consolidação e ampliação das redes públicas de ensino, com 
exceção de algumas poucas políticas gestadas no interior do Governo Federal7. O princípio de descentralização, que perpassa a história e a política educacional brasileira, levou à criação de sistemas estaduais e municipais de ensino com relativa autonomia em relação ao poder central e total autonomia entre si. Após as mudanças instituídas pela Constituição Federal de 1988, que retirou os municípios da condição de subsistemas dos estados e conferiuIhes certo grau de autonomia na relação com os demais entes federados, a Lei de Diretrizes e Bases da Educação Nacional (LDB), Lei n. ${ }^{\circ}$ 9.394/96, estabeleceu a possibilidade de criação dos sistemas municipais de ensino.

A LDB apresenta a possibilidade de os municípios optarem por assumir sua condição como sistema, integrarse ao sistema estadual de ensino ou compor com ele um sistema único. A autonomia presente na relação entre os sistemas de ensino municipais, estaduais e federal gera concomitância entre normas bastante diferenciadas entre os sistemas. E, como os sistemas convivem no mesmo espaço geográfico, isso implica coexistência de normatização, muitas vezes divergente, que regula estabelecimentos de ensino fixados em um mesmo município, mas que compõem sistemas distintos.

Embora o regime de colaboração ou detalhamento do pacto federativo entre União, estados e municípios não tenha sido regulamentado, o próprio texto da Constituição Federal indica que há responsabilidade compartilhada entre os entes federados no que tange à oferta de educação escolar, sobretudo na Educação Básica. A distribuição de competências definida pela Constituição Federal e a LDB atribuiu aos municípios a responsabilidade pela oferta de educação infantil e, com prioridade, do Ensino Fundamental, ressaltando o caráter colaborativo e cooperativo da atuação dos estados e da União. Os estados são responsáveis, portanto, por assegurar o Ensino Fundamental em colaboração com os municípios, e pela oferta de Ensino Médio a todos que o demandarem. Dessa forma, compreende-se que a educação nacional não é formada por um sistema único de ensino, mas pela articulação entre os sistemas federal, estaduais, municipais e do Distrito Federal.

Nessa distribuição de competências, a União assumiu responsabilidades indiretas com a educação básica, tais como a elaboração de normas gerais, a coordenação da avaliação nacional, o desenvolvimento de ações de cooperação técnica e financeira. Portanto, os dispositivos presentes na legislação e normatização nacionais relacionados aos processos de matrícula dos alunos no Ensino Fundamental são bastante sutis, deixando aos sistemas estaduais e municipais as definições mais específicas sobre procedimentos de ingresso na escola.

As regras gerais estabelecidas pela legislação federal em vigor para o ingresso na Educação Básica ${ }^{9}$ definem critérios diferenciados para cada etapa, de acordo com as especificidades dos níveis de ensino. A matrícula na Educação Infantil destina-se a crianças até 5 (cinco) anos de idade, e até 2016 todas as crianças a partir de 4 anos de idade deverão estar matriculadas. Nessa etapa, o ingresso independe de frequência anterior e a organização das turmas deve respeitar a faixa etária dos grupos de crianças.

Como o atendimento à infância na Educação Infantil ainda não está universalizado, percebe-se a existência de uma demanda reprimida que provoca o crescimento das matrículas nessa etapa da Educação Básica, mesmo com a redução da taxa de natalidade. O percentual de atendimento das crianças de 4 e 5 anos de idade encontra-se acima de $80 \%$ da população nessa faixa-etária nos dois municípios analisados, o que os coloca a grande distância da universalização e indica que a expansão da oferta se mantém como uma necessidade.

O texto do inciso $X$ do Artigo $4 .^{\circ}$ da LDB define como dever do poder público a oferta de "vaga na escola pública de educação infantil ou de Ensino Fundamental mais próxima de sua residência a toda criança a partir do dia em que

7 Dentre elas, é possível citar o MOBRAL (1970-1977) e, mais recentemente, as políticas de fundos para o financiamento da educação. Cabe ressaltar que, em ambos os exemplos, a execução se manteve descentralizada.

8 Sobre os sistemas municipais de ensino, ver Parecer CEB/CNE n. ${ }^{0} 30 / 2000$, relatado pelo Conselheiro Carlos Roberto Jamil Cury.

9 A legislação em vigor define que a educação básica é obrigatória e gratuita dos 4 (quatro) aos 17 (dezessete) anos de idade, 0 que significa que a educação infantil na fase de pré-escola (a partir de 4 anos de idade), o Ensino Fundamental e o Ensino Médio (até 17 anos de idade) são os níveis que compõem o ensino obrigatório no Brasil. 0 prazo para a implementação progressiva da obrigatoriedade e gratuidade nesses níveis da educação básica se encerra em 2016. (Cf. EC n. ${ }^{0}$ 59/09) 
completar 4 (quatro) anos de idade". Essa redação desconsidera que as matrículas habitualmente são organizadas e efetivadas pelos sistemas de ensino antes do início do ano letivo e não à medida que as crianças fazem aniversário. Ainda que não seja interditada a matrícula ao longo do período letivo, ela se manifesta como exceção à regra.

O direito à vaga em escola próxima da residência do estudante, independentemente do nível e modalidade de ensino no qual ele esteja matriculado, já estava presente no texto do Estatuto da Criança e do Adolescente (Lei n. ${ }^{\circ}$ 8.069/90), aprovado antes mesmo da LDB. Esse dispositivo procura garantir que existam vagas nas proximidades da residência de todos os estudantes e implica dever do Poder Público no sentido de garantir o acesso à Educação Básica. Cabe ressaltar que a garantia de vaga em escola próxima da residência do estudante não significa que a legislação determine a obrigatoriedade de matrícula nesta instituição.

Outro aspecto a ser considerado é a ampliação do tempo de escolaridade obrigatória. As crianças com 6 anos de idade, que antes estavam na etapa correspondente à pré-escola, passaram a frequentar o Ensino Fundamental com 9 anos de duração, o que gerou a necessidade de absorver maior número de matrículas, tendo em vista a permanência dos alunos durante mais um ano de escolaridade. Como a tendência histórica e demográfica já indicava redução no número de crianças em idade escolar e o processo de implantação foi gradativo, essa demanda foi rapidamente absorvida pelos estabelecimentos de ensino já existentes.

Desta forma, a análise da normatização para distribuição de oportunidades educacionais em escolas de Ensino Fundamental precisa considerar que tal distribuição se realiza em um contexto onde há vagas em quantidade suficiente para atender a demanda apresentada ao poder público. Esta situação é recente no Brasil e impõe a necessidade de observar que esta distribuição não se esgota apenas no aspecto quantitativo, sendo necessário o aprofundamento da análise em relação aos aspectos qualitativos, sobretudo aqueles que podem contribuir para a produção e o acirramento de segregação e desigualdades.

As políticas estabelecidas pela SME/RJ ${ }^{10}$ desde 2009, para a matrícula no Ensino Fundamental, procuram incentivar a escolha dos pais e a aleatorização da distribuição dos estudantes, por meio de procedimentos informatizados utilizados, principalmente, para a matrícula inicial, mas também em alguns casos de transferências internas (estudantes provenientes de escolas da rede municipal de ensino) ou externas (estudantes oriundos de escolas de outras redes de ensino). Antes disso, as matrículas eram feitas pelas famílias diretamente na escola ou em local específico onde se reuniam um conjunto de escolas organizadas em polos para esse procedimento.

Já as políticas de matrícula instituídas pela SME/Curitiba priorizam a organização da matrícula por um sistema de georreferenciamento das escolas e das residências dos estudantes desde 2000. Mas foi instituído um procedimento informatizado de cadastro de novos estudantes para a matrícula inicial ou para matrícula por transferência de estudantes oriundos de outras redes de ensino que, a partir de 2014, possibilita à família a indicação de instituições de ensino diferentes da indicada pelo georreferenciamento.

Do ponto de vista administrativo, ao final de cada letivo, para a organização das matrículas para o ano seguinte, primeiramente são realizadas as renovações de matrícula dos estudantes que já estão matriculados em estabelecimentos da rede municipal de ensino que ofertam o ano/série subsequente. Depois da renovação das matrículas, na SME/RJ, abre-se o período para transferência por remanejamento dos estudantes matriculados em escolas públicas municipais ou conveniadas que não oferecem o ano/série subsequente. Na SME/Curitiba não há previsão para esta movimentação, pois a quase totalidade das vagas para as séries finais do Ensino Fundamental são oferecidas em escolas da rede estadual de ensino.

Posteriormente à matrícula dos estudantes que já estão na rede de ensino, são abertas as inscrições ou o cadastro para matrícula inicial pela internet para os novos candidatos a vagas de Ensino Fundamental. Depois de encerradas as confirmações das matrículas solicitadas pela internet, abre-se a possibilidade de realização de matrículas novas ou por transferência diretamente nas escolas, no caso da SME/RJ, ou nas escolas e Núcleos

10 A sigla SME/RJ indica Secretaria Municipal de Educação do Rio de Janeiro e a sigla SME/Curitiba indica Secretaria Municipal de Educação de Curitiba. 
Regionais de Educação, no caso da SME/Curitiba. Ou seja, a matrícula por meio do procedimento informatizado, em ambos os casos, tem um período específico para realização. Passado esse período, as matrículas podem ser realizadas diretamente pelas famílias junto aos órgãos do sistema.

É possível supor que tanto o procedimento de distribuição de oportunidades por meio do georreferenciamento (colocado em prática pela SME/Curitiba) quanto o procedimento informatizado (colocado em prática pela SME/ RJ), em certa medida, diminuem o poder discricionário dos órgãos do sistema no momento de efetivação da matrícula, como as práticas de seleção dos estudantes pelos próprios funcionários e gestores das instituições de ensino, comoobservado ao longo da realização da pesquisa que deu origem a este artigo, sobretudo por meio de entrevistas com servidores das SME.

Quando as políticas adotadas restringem a possibilidade da escola interferir na solicitação da matrícula, como fazia antes, observa-se que há uma mudança no centro de poder, deslocado, ainda que por um período de tempo, da escola para outros níveis da burocracia estatal. Nos dois casos,este deslocamento se realizada da escola para a própria SME, que passa a utilizar procedimentos considerados mais impessoais (georreferenciamento com possibilidade de escolha ou distribuição aleatória, considerando as escolhas) para a distribuição das vagas entre os estudantes.

A percepção de servidores municipais entrevistados corrobora esta análise. Para uma diretora de escola da SME/RJ, entrevistada para a realização desta pesquisa ${ }^{11}$, depois da implementação da matrícula informatizada a escola tem menor possibilidade de intervenção sobre o processo de distribuição das crianças nas escolas. Ela relata que quando a matrícula era feita diretamente nas escolas ou nos polos organizados pelas Coordenadorias Regionais de Ensino havia maior possibilidade dos estabelecimentos de ensino realizarem seleção dos estudantes ou reservarem vagas para determinadas famílias.

Uma coordenadora pedagógica12, que atua em outra instituição da rede municipal de ensino do Rio de Janeiro, explica que, depois que as famílias fazem as inscrições pela internet e as vagas são distribuídas, as escolas recebem uma listagem com os estudantes a serem matriculados em cada ano/série. Os pais ou responsáveis precisam comparecer na escola para confirmar a matrícula, que é garantida para a criança à qual a vaga foi atribuída. O estabelecimento de ensino não pode negar a matrícula e não pode destinar a vaga a outra criança.

Uma servidora da SME/Curitiba relata que antes da implantação do modelo de georreferenciamento para a matrícula em Curitiba havia concentração de famílias na frente das escolas consideradas de referência pela comunidade, formando grandes filas durante vários dias para disputar uma vaga. O modelo de planejamento da distribuição com base na localização da escola e da residência acabou com as filas e procurou organizar a distribuição dos estudantes de acordo com o local de moradia e o pertencimento à comunidade onde a escola se encontra.

Outro aspecto que procura conferir maior unicidade aos procedimentos adotados em ambas as SME, é a adoção de cronograma específico para organizar todos os procedimentos, que devem ser seguidos por todos os estabelecimentos de ensino e órgãos intermediários, independentemente de suas possíveis peculiaridades. Entre tais procedimentos, encontram-se os prazos estabelecidos, a realização do cadastramento ou inscrição pela internet, a confirmação da matrícula junto à escola. Além de aspectos mais formais, também se verifica a adoção de critérios que passaram a organizar as decisões sobre a alocação dos estudantes nas escolas que possuem vagas.

É preciso entender esse sistema a partir do conceito de ecologia de mercado baseado em posições fechadas, como sugere Yair (1996), pois a existência de uma estrutura de oportunidades diferenciadas, tendo em vista a hierarquização das instituições de ensino, aliada a uma quantidade fixa de vagas em cada escola, limita a possibilidade de acesso sobretudo aos estabelecimentos que concentram demanda.

11 Entrevista realizada em 31/03/2011.

12 Entrevista realizada em 19/05/2011. 
Compreende-se que, na rede municipal de ensino, novos estudantes só podem ser matriculados se houver vaga disponível e isso só é possível se alguém sai do sistema ou deixa de ocupar a vaga por outro motivo, como um pedido de transferência, por exemplo. Assim, ressalta-se que a escolha possibilitada pelos procedimentos não depende apenas de motivações individuais das famílias que a realizam, pois a estrutura de oportunidades existente produz o campo para a realização dessas escolhas.

As vagas existentes são distribuídas para os alunos inscritos pela internet considerando as prioridades estabelecidas pela normatização municipal. No caso da SME/Curitiba, o critério de prioridade é a proximidade entre a escola e a residência do estudante,considerando ainda as opções apresentadas pelas famílias. No caso da SME/RJ, adistribuição das vagas é realizada tendo como principal critério a escolha indicada pelas famílias, de forma randomizada por nível de opção. E, quando há mais demanda do que vagas nas escolas solicitadas, é realizado um sorteio entre os inscritos considerando critérios de prioridadeque podem passar por mudanças a cada ano, uma vez que são definidos por meio de Portarias e Resoluções do Poder Executivo municipal ${ }^{13}$.

Nos dois casos analisados percebe-se a existência de estruturas de posições fechadas, com número limitado de vagas em cada instituição de ensino, como discute Yair (1996). As políticas implementadas procuram conferir maior impessoalidade aos processos de alocação dos estudantes em tais posições ao mesmo tempo em que incorporam, ainda que em diferentes graus, modelos que consideram as escolhas das famílias. O modelo de distribuição adotado pela SME/RJ toma as escolhas das famílias como o critério prioritário para a alocação do estudante enquanto a SME/Curitiba toma as escolhas como elemento secundário.

Em que pesem as diferenças e a importância mais acentuada conferida pela SME/RJ às opções indicadas pelas famílias, é possível afirmar que em ambas as situações as escolhas estão formalmente incluídas na política de matrícula. Contudo, isso não significa que outras formas de acesso à escola não estejam operando de forma paralela, possibilitando a continuidade de práticas com caráter clientelista, que procuram atender demandas individuais de maneira pouco transparente. A coexistência entre procedimentos de escolha formal e outras formas de acesso às escolas da SME/RJ foi identificada por Bruel (2014) e tem sido objeto de análise também em pesquisa junto à SME/Curitiba.

O acesso à informação também se apresenta como um elemento de grande relevância para as políticas de escolha analisadas na primeira parte deste artigo. A informação sobre os estabelecimentos de ensino é considerada como um fundamento da política de escolha, sem a qual a tomada de decisão se torna inviável e possivelmente enviesada. Para Glenn (2009), a informação é parte central da política de escolha controlada, sem a qual o próprio princípio de escolha se torna ameaçado.

Para Felouzis et al. (2013), o funcionamento de quase-mercados escolares é fortemente dependente da existência de informações sobre os estabelecimentos de ensino, sua disponibilização e lisura. Segundo os autores, "pour qu'un choix soit 'libre' et rationnel, encore faut-il qu'il soit informé." (FELOUZIS et al., 2013, p. 24) ${ }^{14}$ No caso da educação, é preciso considerar que a informação pode estar desigualmente distribuída entre a população, em razão do capital escolar e social. Ainda que os casos em análise não possam ser identificados como políticas de quase-mercados educacionais, a implementação de procedimentos de escolha exige a disponibilização de conhecimentos sobre a rede de ensino que a orientem e a informem, sem provocar ainda maiores desigualdades entre aquelas famílias que conhecem os sistemas de ensino e as que não.

As informações disponíveis nos sites da SME/RJ e da SME/Curitiba referem-se à divulgação de datas e procedimentos para realização do cadastramento e inscrição pela internet. Os dois sistemas apresentam formas de

13 As prioridades definidas em 2010 eram 0 atendimento aos candidatos: a) com deficiências; b) que possuam irmãos frequentando a mesma escola; c) Filhos de servidores lotados na mesma escola; d) Filhos adotivos amparados pela Lei Municipal $n .{ }^{\circ} 2.210$ de 21/07/1994; e) Candidatos oriundos de orfanatos. (Portaria E/SUBG/CP n. 24, de 22 de outubro de 2010)

14 Tradução livre: para que uma escolha seja livre a racional, exige-se que ela seja informada. (FELOUZIS at al., 2003, 0. 24) 
busca aos estabelecimentos municipais de ensino, mas não há informações sobre cada um deles em relação aos projetos pedagógicos, forma de organização, ou outras características que possam ser consideradas relevantes para informar as escolhas das famílias ${ }^{15}$. O acesso ao formulário de inscrição e ao resultado do procedimento depende do período em que estes itens ficam disponíveis, de acordo com o cronograma estabelecido.

\section{Considerações finais}

Mudanças relevantes podem ser reconhecidas nas políticas em análise, sobretudo com o deslocamento dos processos de matrícula do âmbito das escolas e órgãos intermediários da burocracia da rede de ensino para sistemas informatizados, que podem conferir um caráter mais impessoal para o procedimento de alocação dos estudantes nos estabelecimentos de ensino nas redes estudadas. Há, ainda que durante períodosespecíficos, uma intervenção da administração municipal no sentido de criar barreiras aos processos de seleção dos estudantes pelas escolas.

Percebe-se a existência de características semelhantes entre aspectos do modelo de distribuição de vagas adotado pela SME/RJ a partir de 2010 e pela SME/Curitiba a partir de 2014 com políticas de escolha da escola apresentadas neste artigo. Ainda que não se possa afirmar que as políticas municipais sejam políticas de school choice, é possível supor que seus formuladores buscaram inspiração em modelos que se encontram em vigor nos Estados Unidos e Inglaterra. No caso específico da SME/Curitiba, observa-se também forte influência do modelo de georreferenciamento adotado pela política de alocação de estudantes na França, o que não foi tomado como foco deste artigo.

Em vários dos casos analisados na primeira parte deste artigo há uma mudança na esfera de tomada de decisão, criando oportunidade para expressão de opção das famílias e transferindo o procedimento de alocação dos estudantes para níveis hierárquicos mais elevados do sistema de ensino. Mas há vários aspectos dos modelos adotados pelas redes municipais de ensino do Rio de Janeiro e de Curitiba que os diferenciam de outras políticas presentes no cenário internacional.

No que tange à aleatorização da distribuição das vagas entre os candidatos na política implementada pela SME/RJ, é possível afirmar que as mudanças na normatização e nas práticas de alocação dos estudantes ainda são um pouco tímidas, na medida em que não abrangem todas as formas de acesso, tampouco todas as etapas da Educação Infantil e do Ensino Fundamental, além de serem limitadas pelos critérios definidos como prioridade de atendimento. No caso da política de matrícula da SME/Curitiba não há aleatorização da distribuição e as escolhas são consideradas de maneira ainda mais tímida e secundarizada.

Em nenhum dos dois casos analisados há elementos que remetam à busca de equilíbrio na composição da população que frequenta a escola a partir de critérios que possam reduzir a segregação no interior das redes de ensino. As políticas de school choice analisadas usualmente adotam critérios baseados em origem étnico-racial, indicadores de pobreza ou de desigualdade para a distribuição dos estudantes nos estabelecimentos de ensino a fim de garantir algum equilíbrio entre as escolas e diminuir os índices de segregação no interior das redes (GORARD et al, 2003; GLENN, 2009). Nas políticas implementadasem ambos os municípios, não foi possível detectar a utilização de critérios de distribuição com esse objetivo.

Foi possível perceber que há pouca divulgação a respeito dos momentos de escolha da escola pela internet e, principalmente, há pouca ou nenhuma informação sobre os estabelecimentos que compõem a rede municipal e oferecem vagas. Uma das grandes preocupações das políticas de school choice analisadas é a garantia de divulgação de dados sobre as instituições de ensino a fim de informar as escolhas das famílias. Mas esta preocupação não se revelou presente na normatização, nas entrevistas realizadas com funcionários das duas SME ou nas visitas aos sites oficiais de matrícula.

15 Fonte: https://matriculadigital.rioeduca.rio.gov.br, acessado em 14/11/2013, 05/12/2013, 03/01/2014; http://www.cidadedoconhecimento.org.br, acessado em 03/08/2016. 
A descrição da normatização e das práticas relacionadas aos processos de matrícula dos estudantes nas redes municipais de ensino analisadas indica a coexistência de vários procedimentos para a realização de matrícula e transferências de estudantes entre escolas. Os procedimentos tradicionalmente instituídos no âmbito das redes municipais de ensino convivem com as novas formas de distribuição dos estudantes nos estabelecimentos escolares.

Tanto as escolas quanto as famílias estão ainda passando por um período de transição e adaptação aos novos formatos de apresentação da demanda por vagas e de seu atendimento. É possível afirmar que as políticas municipais em foco têm se pautado pela restrição da seleção dos estudantes por parte dos estabelecimentos, transferindo os processos de matrícula para procedimentos mais impessoais e centralizados pela administração municipal. Nos dois casos verifica-se a possibilidade de escolha dos pais, ainda que em graus bastante diversos. Enquanto a política implementada pela SME/RJ incentiva a escolha das famílias, a implementada pela SME/Curitiba prevê a sua existência, mas de forma secundária. De todo modo, verificam-se fragilidades tanto na tentativa de restrição de seleção dos estudantes pelas escolas quanto de incentivo ao atendimento da escolha das famílias, o que denota a necessidade de aprofundamento das reflexões aqui apresentadas.

\section{Referências}

BRUEL, A. L. Distribuição de oportunidades educacionais: o programa de escolha da escola pela família na rede municipal de ensino do Rio de Janeiro. Tese de doutoramento. UFRJ: Rio de Janeiro, 2014.

COSTA, M. e KOSLINSKI, M. Escolha, estratégia e competição por escolas públicas - pensando a ecologia do quase-mercado escolar. Trabalho apresentado no 33. ${ }^{\circ}$ Encontro Anual da ANPOCS. Caxambu, 2009.

FELOUZIS, MAROY e VAN ZANTEN. Les Marchés Scolaires. Sociologie d'une politique publique d'éducation. Paris: Presses Universitaires de Frances, 2013.

GLENN, C. School Segregation and Virtuous Markets. Communication présentée au colloque "Penser les marches scolaires" Rappe - Université de Genève - Mars 2009.

GORARD, S.; TAYLOR, C.; FITZ, J. Schools, markets and choice policies. New York: Routledge Falmer, 2003.

MAROY, C. École, régulation et marché. Une comparaison de six espaces scolaires locaux en Europe. Presses Universitaires de France: Paris, 2006.

POUPEAU, F. e FRANÇOIS, J. C. Le sens du placement. Ségrégation résidentielle et segregation scolaire. Paris: Raisons d'Agir Éditions, 2008.

RIO DE JANEIRO. Secretaria Municipal de Educação. Portaria E/SUBG/CP n. 24, de 22 de outubro de 2010. Publicada no D.O. RIO de 26/10/2010, p. 013.

RESENDE, T. F.; NOGUEIRA, C. M. M.; NOGUEIRA, M. A. Escolha do estabelecimento de ensino e perfis familiares:uma faceta a mais das desigualdades escolares. Educação e Sociedade [online]. 2011, vol.32, n.117, pp. 953-970. ISSN 0101-7330.

VAN ZANTEN, A. Choisir son école. Stratégies familiales et médiations locales. Paris: Presses Universitaires de France, 2009.

YAIR, G. School Organization and Market Ecology: a realist sociological look at the infrastructure of school choice. In: British Journal of Sociology of Education, vol. 17, n. 4, 1996. pp. 453-471.

Recebido em março de 2016 | Aprovado em maio de 2016 